\title{
The Immediate Effect of Muscle Energy Technique and Whole Body Vibration on Hamstring Muscle Flexibility and Stiffness in Healthy Young Females
}

\author{
M. Azizi ${ }^{1}$, A. Shadmehr², K. Malmir², N. Qotbi ${ }^{2}$, Z. Khazaei Pour ${ }^{3}$ \\ 1 Department of Physiotherapy, School of Rehabilitation, Tehran University of Medical Sciences, Tehran, Iran \\ 2 Brain and Spinal Cord Injury Research Center, Neuroscience Institute, Tehran University of Medical Sciences, \\ Tehran, Iran
}

\section{CORRESPONDING AUTHOR: \\ Azadeh Shadmehr \\ Department of Physiotherapy \\ School of Rehabilitation \\ Tehran University of Medical Sciences \\ Tehran, Iran \\ E-mail: Shadmehr@tums.ac.ir}

DOI:

10.32098/mltj.03.2021.04

LEVEL OF EVIDENCE: 1B

\begin{abstract}
SUMMARY
Background. High prevalence of hamstring injury is attributable to the lack of efficient flexibility, and different methods are suggested for increasing its flexibility. Therefore, the present study investigated two methods in healthy young females, Muscle Energy Technique (MET) and Whole Body Vibration (WBV) on flexibility and Hamstring Muscle Stiffness. Materials and methods. Fifty-six young females were included in the sample with a mean age of $23.82 \pm 3.17$ years and were randomly placed in one of two treatment groups. The participants were treated 3 times with the Post Isometric Relaxation technique in the MET group. In the WBV group, in three 30 -second sets at $30 \mathrm{~Hz}$ and $2 \mathrm{~mm}$ amplitude, each participant was subjected to vibration. Active Knee Extension (AKE) and Modified Sit \& Reach (Mod S \& R) tests measured Hamstring flexibility, and the Stiffness evaluation was carried out using the Biodex system 3.

Results. The evaluation results revealed a significant difference between pre-intervention and post-intervention $(\mathrm{P}=0.000)$, but therewasnosignificant differencebetween the two treatment groups in terms of post-intervention test results $(P>0.000)$.

Conclusions. The results showed that a single WBV and MET session increased flexibility and decreased the stiffness of the hamstring, but there was no substantial difference in the efficacy of these methods.
\end{abstract}

KEY WORDS

Flexibility; range of motion; stiffness; Muscle Energy Technique (MET); Whole Body Vibration (WBV).

\section{INTRODUCTION}

Flexibility refers to the elongation of skeletal muscles and tendons and is generally considered an important rehabilitation protocol component $(1,2)$. Two concepts, static and dynamic, provide flexibility. Static flexibility is the threshold of muscle tolerance towards stretching and can be measured by movement range. Dynamic flexibility also refers to the amount of resistance (active or passive) that tissue creates against stretching, also named stiffness (2). The creation of passive resistance to length variation is the responsibility of parallel elastic connective tissues such as sarcolemma, endomysium, perimysium, and epimysium. In contrast, series structures such as tendons and cross bridges of muscles are involved in creating active stiffness. Therefore, stiffness and flexibility are distinct concepts and cannot be considered synonyms (3).

Normal flexibility is essential to maintaining an ideal posture and perform activities smoothly. The hamstring is an important two-joint muscle, which is highly susceptible to shortening. This muscle is the largest knee flexor (4), and has a strong tendency to shortness due to its two joints structure, its tonic postural property, and 
tension production continuously (5). Hamstring shortness may cause primary and secondary injuries such as increased strain risk, reduced joints range of motion, patellofemoral pain syndrome, plantar fasciitis, failure of lumbopelvic rhythm, and low back pain $(6,7)$.

Muscle Energy Technique (MET) is a type of manual therapy technique accompanied by an isometric contraction of target muscle and increases muscle flexibility (8). Various studies have found that the MET may have more effect than static stretching because it reduces pain and discomfort and generally makes further changes either as acute or long term forms in the target tissue (9-14).

Whole Body Vibration (WBV) is another relatively new method that has recently become a popular modality in the rehabilitation and sports domain (15-20). WBV is a safe and easy method to use that transfers vibrations through a platform to the whole or certain parts of the body (21). WBV platforms transmit vibrations in two ways. The first type is Synchronous, which transmits vibration to both legs simultaneously and applies a straight linear acceleration to the trunk. The second type is Side-alternating, which transmits vibrations intermittently, so when the right leg is at the lowest amplitude level, the left one is at the highest. This type of platform causes rotational movements in the hip and lumbosacral joints. It leads to less vibration load to be transmitted to the trunk so that more acceleration can be applied to the body through it $(22,23)$.

Since the influence on muscle stiffness as a biomechanical factor of either of these two therapeutic methods has not yet been studied, we agreed to compare the immediate effect of MET and WBV on hamstring flexibility and stiffness in healthy young females.

\section{METHODS}

\section{Design}

We randomly assigned participants to the two MET and WBV classes using a balanced block randomization method in the current randomized, controlled trial between April 2018 and December 2018. The Ethics Committee of Tehran University of Medical Sciences approved the research. The biomechanics laboratory of the Rehabilitation Faculty of Tehran University of Medical Sciences conducted all of the interventions and assessments.

\section{Participants}

According to the Active Knee Extension test, 56 healthy young women with the extension lack of 20 degrees or more at their popliteal angles volunteered to participate in the study through advertisements distributed to the faculty. The inclusion criteria were as follows:

- female ages between 18-30 years;

- 20 degree or more lack of extension during active knee extension test (4);

\section{- $\quad$ BMI of 18/5-29/5.}

The exclusion criteria were as follows: cardiovascular and respiratory diseases, chronic neurological and vestibular musculoskeletal diseases, pregnancy, epilepsy, seizure and migraine, severe deformities of lower extremities and the presence of prosthesis, previous hamstring injuries (25), attending in training programs continuously 3 days a week, feeling pain, fear or discomfort during intervention and evaluation, lack of good collaboration at each stage of the study, disclaimer from participation in the study. All of the participants read and signed informed consent forms before participating in the study.

\section{Procedures}

Hamstring flexibility was measured by two tests:

1. active knee extension test (AKET): the participant lay down in a supine position, and straps fastened the trunk and another leg to fix the pelvis and prevent its movement. A wooden cube with dimensions of $35 \times 38$ $\times 30 \mathrm{~cm}$ was then fixed behind the thigh to maintain the hip joint at 90 degrees of flexion. We asked the participant to keep the knee straight as much as possible, and its popliteal angle was measured using the goniometer (instrument model, etc.) (6).

2. Modified Sit \& Reach test (Mod S \& R): the participant sat on the floor while her back and head were against the wall and placed her bare feet against the front wall of the flex tester box. First, the participant pulled hands forward without removing the back and head from the wall and considered the origin or zero's fingertip location. In the next step, the participant completely bent her back with knees in extension position and pulled hands forward on the box. The distance between the fingertips from the point of origin or zero was considered the test result.

To determine the hamstring stiffness, the participant sat on the seat of Biodex system 3 (Medical system, etc.), and straps fixed the trunk and hip. Device settings included passive mode, the angular velocity of $5 \% \mathrm{sec}$, and the range of motion from the flexion to the end of active knee extension. At the beginning of the test, the device moved the participant's knee passively with a specified angular velocity to the existing extension's end. Since the highest stiffness exists at the end of the length of muscles, the final $30^{\circ}$ of the extension was considered as the angular posi- 
tion. According to the definition of stiffness, the passive hamstring torque was calculated at the final $30^{\circ}$ of the passive knee extension (26):

$$
\text { Stiffness }=\frac{\Delta \text { Torque }}{\Delta \text { Angular position }}
$$

\section{Muscle Energy Technique (MET) treatment group}

In the MET group, the Post isometric relaxation technique (Lewit method) was performed to increase hamstring flexibility. The participant lay in a supine position, and the hip was fixed at 90 degrees of flexion, and the knee joint was taken passively to the extension until the restrictive barrier. We then asked the participant to put pressure towards the direction of knee flexion with $75 \%$ of Maximal voluntary contraction (MVC) against the applied force by the therapist $(25,27)$ and hold it for 7-10 seconds $(8)$. The participant relaxed the muscle, and the knee was taken passively to the new range of extension by the therapist. This technique was repeated 3 times at intervals of about 10 seconds $(25,28)$.

\section{Whole body vibration (WBV) treatment group}

In the WBV group, the participants stood on the platform of Powerplate (next generation, etc.) without shoes and socks with bending knees (about 20 degrees) while their legs were open as much as the shoulder width and put under the vibration at a frequency of $30 \mathrm{~Hz}$ and 2 $\mathrm{mm}$ of amplitude. This situation prevents vibration transfer to the head (29). Each participant was treated in three 30 -seconds sets with 30 seconds of rest between each set. According to the following equation:

$A_{\text {Peak }}=A \omega^{2}\left(\mathrm{~m} / \mathrm{s}^{2}\right)=A(2 \pi f)^{2}=0.002(2 \times 3.14 \times 30)^{2} \approx 7 g$

The amount of applied acceleration to body was approximately $7 \mathrm{~g}\left(\mathrm{~g} \approx 9.8 \mathrm{~m} / \mathrm{s}^{2}\right)(22)$.

The reassessment was repeated in both groups after 5 minutes of rest (30).

\section{Statistical analysis}

The data was analyzed statistically using version 22 of the SPSS. First of all, to determine the data normality, the one-sample Kolmogorov-Smirnov test was used; and its results indicated the normal distribution of the data $(\mathrm{P}>$ 0/05); therefore, the Paired T-test was used in each group to compare pre-post. An Independent t-test was also used to compare the changes after the interventions in AKE, Mod S $\& \mathrm{R}$, and stiffness between the two groups.

\section{RESULTS}

The participant's eligibility criteria are summarized in figure 1. The data was collected from 56 young females with hamstring tightness, and their anthropometric characteristics, including participants' age, height, weight, and BMI based on the Mean + SD presents in table I. Also, the results of AKE, Mod S\&R, and stiffness test in each group shown in table II. According to the Paired t-test, There was a significant difference between before and after the variables in each group of WBV and MET $(\mathrm{P}<0 / 05)$. The results of the independent $t$-test indicated that there was no significant difference between MET and WBV groups regarding increasing flexibility and decreasing stiffness $(\mathrm{P}>0 / 05)$ (table III).

Table I. Anthropometric data of participants in each group $(\mathrm{N}=56)$.

\begin{tabular}{|c|c|c|c|c|c|}
\hline Group & Variable & $\mathbf{N}$ & Mean & SD & Range \\
\hline \multirow{3}{*}{ MET } & Age (year) & \multirow{3}{*}{28} & 24.18 & 3.23 & $19-29$ \\
\hline & Height $(\mathrm{cm})$ & & 162.71 & 5.83 & $150-174$ \\
\hline & Weight (kg) & & 65.14 & 6.95 & $52-75$ \\
\hline \multirow{3}{*}{ WBV } & Age (year) & \multirow{3}{*}{28} & 23.46 & 3.13 & $18-28$ \\
\hline & Height $(\mathrm{cm})$ & & 161.57 & 3.82 & $156-170$ \\
\hline & Weight (kg) & & 61.46 & 5.51 & $49-71$ \\
\hline
\end{tabular}

Table II. The comparison of variables before and after of MET and WBV according to the Mean \pm SD (N = 56).

\begin{tabular}{llllll}
\hline MET $(\mathbf{N}=\mathbf{2 8})$ & \multicolumn{5}{c}{ WBV $(\mathbf{N}=\mathbf{2 8})$} \\
\hline & Pre & Post & P-Value & Pre & Post \\
\hline $\begin{array}{l}\text { AKE } \\
(\text { Degree })\end{array}$ & $62.17 \pm 8.04$ & $73.41 \pm 8.07$ & 0.000 & $63.93 \pm 8.72$ & $74.5 \pm 8.85$ \\
\hline $\begin{array}{l}\text { Mod S\&R } \\
(\mathbf{c m})\end{array}$ & $20.64 \pm 4.88$ & $23.39 \pm 4.94$ & 0.000 & $20.71 \pm 5.15$ & $23.12 \pm 5.02$ \\
\hline $\begin{array}{l}\text { Stiffness } \\
(\mathbf{N m} / \text { Rad })\end{array}$ & $12.2 \pm 2.5$ & $10.46 \pm 2.36$ & 0.000 & $11.97 \pm 2.84$ & $10.41 \pm 2.84$ \\
\hline
\end{tabular}

Legend: KE, Active Knee Extension; Mod S \& R, Modified sit and reach; MET, Muscle Energy Technique; WBV, Whole Body Vibration. 
Table III. The comparison of studie's variable between two treatment groups according to the Mean difference \pm SD $(\mathrm{N}=56)$.

\begin{tabular}{lccl}
\hline & MET $(\mathrm{N}=28)$ & WBV $(\mathbf{N}=28)$ & P-Value \\
\hline $\begin{array}{l}\text { AKE } \\
(\text { Degree })\end{array}$ & $11.23 \pm 1.63$ & $10.64 \pm 1.68$ & 0.188 \\
\hline $\begin{array}{l}\text { Mod S \& R } \\
(\mathbf{c m})\end{array}$ & $2.75 \pm 0.88$ & $2.41 \pm 0.85$ & 0.147 \\
\hline $\begin{array}{l}\text { Stiffness } \\
(\mathbf{N m} / \text { Rad })\end{array}$ & $1.77 \pm 0.63$ & $1.55 \pm 0.6$ & 0.197 \\
\hline
\end{tabular}

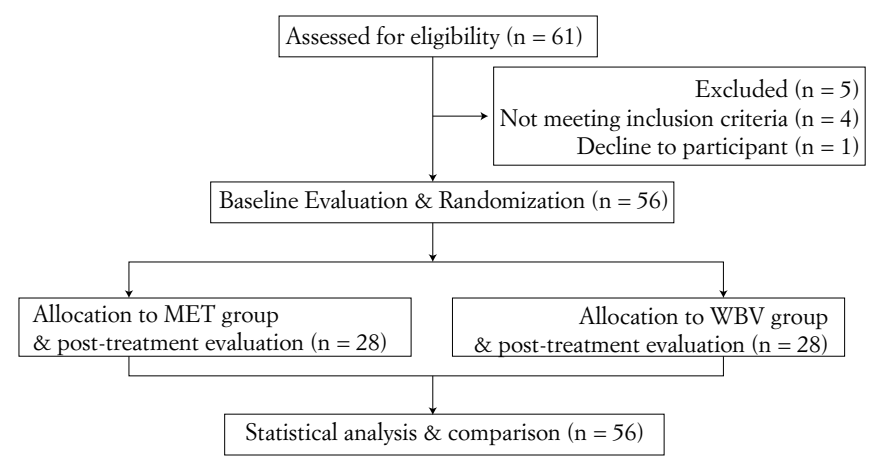

Figure 1. Flowchart of enrollment and testing procedure.

\section{DISCUSSION}

Results indicated increase flexibility and reduction of hamstring Stiffness after the MET intervention. Despite the difference of the present study in methodology, sample size, and even gender of participants, results of the flexibility evaluation in the present study were consistent with results of previous that all reported the effectiveness of MET on hamstring flexibility $(8,9,27)$. Some studies also compared this method with other techniques such as static stretching, for instance, Shadmehr's studies in 2009 and Ahmed in 2010. However, the results of these studies indicate the relatively similar effects of both methods on increasing flexibility. However, evidence suggests that apparently the MET has a more prolonged effect on the tissue and can reduce pain and discomfort by affecting the Gate control and the tolerance threshold, and can generally make more changes than static stretching $(9,25,28)$. MET's impact on flexibility can result from the inhibitory reflex of the Golgi tendon organ that creates relaxation in the muscle and reduces its resistance to stretch following by an active isometric contraction. Viscoelastic changes, which occur in the muscle and surrounding structures as mechanical factors, and changes in tolerance threshold toward stretching as neurophysiological factors can also increase the hamstring flexibility after the $\operatorname{MET}(9,31,32)$.
Passive muscle mechanical structures are manifestations of the Stiffness property. Specific factors include the number of cross-links between actin and myosin filaments, endosarcomycal and exosarcomic non-contractile proteins, and deformation caused by connective tissues around the bulk of the muscle may be responsible for their resistance production. The measurement of the amount of musculotendinous stiffness is commonly used for assessing characteristics of these passive structures (33) because Hatano also expresses that the amount of passive stiffness of muscle is associated with the amount of viscoelasticity of musculotendinous unit. Contrary to other factors, the passive resistance to articular movements is mainly due to these elastic structures (34). It can be concluded that the stiffness decreasing after the intervention of MET is due to viscoelastic changes in the musculotendinous unit. Agonist/Antagonist co-contraction also changes the amount of joint stiffness; as in this study, we immediately saw increased flexibility and decreased stiffness after the MET intervention. Hence, any factor, which decreases the co-contraction and increases the relaxation, can reduce the amount of stiffness as the MET creates relaxation and decreases the co-contraction force through the inhibition reflex of the Golgi tendon (3, 32). A reason for the triple repetition of the stiffness test was the individuals' unfamiliarity with the device and test conditions leading to unnecessary contractions in lower limb muscles. Subsequently, more production torque was measured by the hamstring muscle, and more stiffness was calculated than the subsequent trials. Therefore, the MET created relaxation in the hamstring and decreased its produced torque through the inhibitory Golgi tendon reflex. It could cause a decrease in stiffness according to the definition of stiffness as the ratio of produced torque to the angular position $(3,31)$.

In the WBV treatment group, results indicated the immediate positive effect of the intervention on flexibility and stiffness variables. The previous studies also achieved similar results for the comparison of WBV with other therapeutic methods in determining the amount of flexibility $(30,35)$, but there was no study to examine changes in stiffness for comparing results of the present study with them.

Vasodilation and increased circulation occur after using the WBV and can affect contractile characteristics and muscular viscoelasticity $(36,37)$. Kerschan-schindle also noted that the blood flow rate is doubled in the popliteal artery following by a 9-minute vibration (38). It should be noted that vasodilation is a temporary immediate phenomenon and cannot be cited probably in explaining the long term effects of Vibration on variables such as Flexibility and Stiffness. Tonic vibration reflex is a neurophysiological mechanism involved in the effectiveness of WBV, and it is activated in response to the vibration and results in an increase in agonist muscle tone. Therefore, 
the stimulation of the muscle spindle activates the pathway of the stretch reflex. This pathway always causes the agonist muscle contraction (quadriceps) and inhibits and reduces the activity of the antagonist (hamstring), leading to the increased hamstring flexibility, decreased production of torque, and subsequently decreased stiffness $(36,39)$. Bosco and Cardinal also pointed out that vibrations inhibited the activity of antagonist muscles via Ia inhibitory interneurons. Therefore, the activation of quadriceps causes hamstring relaxation and, consequently, positive effects on stretching exercises (40).

Proprioceptive feedbacks, which are involved in the pain control, can also increase the tolerance to stretching and increase the range of motion by enhancing the tolerance threshold $(41,42)$. Issurin also concluded that the pain was reduced 10-15 seconds after the start of stretching and vibrational interventions (39).

In general, the WBV can increase the range of motion by increasing the tolerance threshold to stretching, increasing focal heat and vasodilation, and leading to increased flexibility and decreased Stiffness by controlling the activity of hamstring muscle reducing its produced torque.

On the other hand, the present study's results indicated similar effects of MET and WBV on the study variables. Both interventions had the same impact on variables, and no significant difference was found between their results. As mentioned earlier, the MET intervention through mechanisms such as the inhibitory reflex of the Golgi tendon, making viscoelastic changes, increasing the tolerance threshold, and reducing the co-contraction of muscles around the joint can immediately increase the flexibility and reduce stiffness $(3,31,32,37)$. Like the same mechanisms, the WBV intervention causes immediate changes in studied variables, including the increased local heat and viscoelastic changes, increased pain tolerance threshold, tonic vibration reflex that ultimately causes agonist muscle activity (quadriceps) and inhibits the antagonistic muscle (hamstring) (37, 42, 43). The mechanisms of these two therapeutic approaches'

\section{REFRENCES}

1. Depino GM, Webright WG, Arnold BL. Duration of maintained hamstring flexibility after cessation of an acute static stretching protocol. J Athl Training 2000; 35(1):56-9.

2. Gleim GW, McHugh MP. Flexibility and its effects on sports injury and performance. Sports Med 1997;24(5):289-99.

3. Blackburn JT, Riemann BL, Padua DA, Guskiewicz KM. Sex comparison of extensibility, passive, and active stiffness of the knee flexors. Clin Biomech 2004;19(1):36-43.

4. Mhatre BS, Singh YL, Tembhekar JY, Metha A. Which is the better method to improve perceived hamstrings tightness? effectiveness seem to be relatively similar and can immediately affect flexibility and stiffness in similar ways. However, it is better to conduct a long-term analysis on comparing the effects of these two interventions to assess the consistency of their effects to determine precisely if these two methods are always the same or are their short-term effects just the same for affecting biomechanical variables. Furthermore, we can compare the stiffness and other variables in these two treatment methods between males and females to find out whether changes in the amount of stiffness and flexibility between the two sexes are the same or not.

\section{CONCLUSIONS}

The present study indicated that a single session of using WBV and MET could immediately increase the hamstring flexibility and immediately decrease its stiffness. According to a comparison of these two methods, both interventions had the same effects on studied variables. No significant difference was found between the effectiveness of any two methods on flexibility and stiffness. Therefore in cases such as improving muscle flexibility immediately before starting training or sports competitions, both of these two treatment methods can be accomplished. The study meets the ethical standards of the journal (44).

\section{ACKNOWLEDGMENTS}

The research was supported by the Tehran University of Medical Sciences (TUMS) and Health Services (Grant no.: 98-01-32-39971). We would thank all the participants who participated in the present study and the personnel of the School of Rehabilitation.

\section{CONFLICT OF INTERESTS}

The authors declare that they have no conflict of interests.

Exercises targeting neural tissue mobility or exercises targeting hamstrings muscle extensibility? Int J Osteopath Med 2013;16(3):153-62.

5. Medeiros DM, Cini A, Sbruzzi G, Lima CS. Influence of static stretching on hamstring flexibility in healthy young adults: Systematic review and meta-analysis. Physiother Theory Pract 2016;32(6):438-45.

6. Kuilart KE, Woollam M, Barling E, Lucas N. The active knee extension test and Slump test in subjects with perceived hamstring tightness. Int J Osteopath Med 2005;8(3):89-97. 
7. McCarthy JJ, Betz RR. The relationship between tight hamstrings and lumbar hypolordosis in children with cerebral palsy. Spine J 2000;25(2):211-3.

8. Smith M, Fryer G. A comparison of two muscle energy techniques for increasing flexibility of the hamstring muscle group. J BodyW Mov Ther 2008;12(4):312-7.

9. Ballantyne F, Fryer G, McLaughlin P. The effect of muscle energy technique on hamstring extensibility: the mechanism of altered flexibility. J Osteopath Med 2003;6(2):59-63.

10. Cornelius WL,Ebrahim K, Waston J, Hill DW. The effects of cold application and modified PNF stretching techniques on hip joint flexibility in college males. Res Q Exerc Sport 1992;63(3):311-4.

11. Handel M, Horstmann T, Dickhuth H, Gulch RW. Effects of contract-relax stretching training on muscle performance in athletes. European J Applied Physiol Occupational Physiol 1997;76(5):400-8.

12. Magnusson SP, Simonsen EB, Aagaard P, et al. Mechanical and physiological responses to stretching with and without preisometric contraction in human skeletal muscle. Archives Phys Med Rehab 1996;77(4):373-8.

13. Wallin D, Ekblom B, Grahn R, Nordenborg T. Improvement of muscle flexibility: a comparison between two techniques. Am J Sports Med 1985;13(4):263-8.

14. Sady SP, Wortman M, Blanke D. Flexibility training: ballistic, static or proprioceptive neuromuscular facilitation? Archives Phys Med Rehab1982;63(6):261-3.

15. Karatrantou K, Gerodimos V, Dipla K, Zafeiridis A. Whole-body vibration training improves flexibility, strength profile of knee flexors, and hamstrings-to-quadriceps strength ratio in females. J Sci Med Sport 2013;16(5):477-81.

16. Yoosefinejad AK, Shadmehr A, Olyaei G, Talebian S, Bagheri H, Mohajeri-Tehrani MR. Short term effects of the whole body vibration on the balance and muscle strength of type 2 diabetic patients with peripheral neuropathy: a quasi-randomized-controlled trial study. J Diab Metabol Dis 2015;14(1):45.

17. Ashnagar Z, Shadmehr A, Talebian S, Jalaei S. The immediate effects of whole body vibration on timing parameters in the upper extremity muscles of healthy young women. J Mod Rehabil 2012;6(1):49-55.

18. Dony Y, Wang H, Zhu Y, et al. Effects of whole body vibration exercise on lumbar-abdominal muscles activation for patients with chronic low back pain. BMC sports Sci Med Rehabil 2020;12(1):78

19. Costantino C, Bertuletti S, Romiti D. Efficacy of whole body vibration board training on strength in athletes after anterior cruciate ligaments reconstruction: a randomized controlled study. Clin J Sport Med 2018;28(4):339-49.

20. Kurt C, Pekunlu E. Acute effect of whole body vibration on isometric strength, squat jump and flexibility in welltrained combat athletes. Biol Sport 2015;32(2):115-22.

21. Tsuji T, Kitano N, Tsunoda K, et al. Short-term effects of whole-body vibration on functional mobility and flexibility in healthy, older adults: a randomized crossover study. J Geriatr Phys Ther 2014;37(2):58-64.
22. Rittweger J. Vibration as an exercise modality: how it may work, and what its potential might be. Eur J Appl Physiol 2010;108(5):877-904.

23. Abercromby AF, Amonette WE, Layne CS, McFarlin BK, Hinman MR, Paloski WH. Vibration exposure and biodynamic responses during whole body vibration training. Med Sci Sports Exerc 2007;39(10):1794.

24. Tsuji T, Kitano N, Tsunoda K, et al. Short-term effects of whole-body vibration on functional mobility and flexibility in healthy, older adults: a randomized crossover study. J Geriatr Phys Ther 2014:37(2):58-64.

25. Ahmed H, Miraj M, Katyal S. Effect of muscle energy technique and static stretching on hamstring flexibility in healthy male subjects. Ind J Phys Occup Ther 2010;4(3):32.

26. Wang D, De Vito G, Ditroilo M, Delahunt E. Effect of sex and fatigue on muscle stiffness and musculoarticular stiffness of the knee joint in a young active population. J Sports Sci 2017;35(16):1582-91.

27. Mazumdar J, Shriwas JK, Wani SK, et al. A comparison between mulligan traction straight leg raise technique vs muscle energy technique on hamstring tightness in asymptomatic Male. Int J Physiother Res 2014;2(2):412-7.

28. Shadmehr A, Hadian MR, Naiemi SS, Jalaie S. Hamstring flexibility in young women following passive stretch and muscle energy technique. J Back Musculoskeletal Rehabil 2009; 22(3):143-8.

29. Gerodimos V, Zafeiridis A, Karatrantou K, Vasilopoulou T, Chanou K, Pispirikou E. The acute effects of different whole-body vibration amplitudes and frequencies on flexibility and vertical jumping performance. J Sci Med Sport 2010;13(4):438-43

30. Soltani A, Shadmehr A, Attarbashi-Moghadam B, Jalali Sh. The effect of whole body vibration on the amount of flexibility of lower limb in young healthy women. SID 2016;5(2):86-95.

31. O'Sullivan K, Murray E, Sainsbury D. The effect of warmup, static stretching and dynamic stretching on hamstring flexibility in previously injured subjects. BMC Musculoskelet Disord 2009;10:37.

32. Shellock FG, Prentice WE. Warming-up and stretching for improved physical performance and prevention of sports-related injuries. Sports Med. 1985; 2(4):267-78.

33. Herda TJ, Costa PB, Walter AA et al. Effects of two modes of static stretching on muscle strength and stiffness. Med Sci Sports Exerc 2011;43(9):1777-84.

34. Hatano G, Suzuki S, Matsuo S, et al. Hamstring Stiffness Returns More Rapidly After Static Stretching Than Range of Motion, Stretch Tolerance, and Isometric Peak Torque. J Sport Rehabil 2017;28(4):325-31.

35. Dallas G, Paradisis G, Kirialanis P, Mellos V, Argitaki P, Smirniotou A. The acute effects of different training loads of whole body vibration on flexibility and explosive strength of lower limbs in divers. Biol Sport 2015;32(3):235-41.

36. Cronin JB, Oliver M, McNair PJ. Muscle stiffness and injury effects of whole body vibration. Physic Ther Sport 2004;5(2):68-74.

37. Rittweger J, Beller G, Felsenberg D. Acute physiological effects of exhaustive whole-body vibration exercise in man. Clin Physiol 2000;20(2):134-42. 
38. Kerschan-Schindl K, Grampp S, Henk C, et al. Wholebody vibration exercise leads to alterations in muscle blood volume. Clin Physiol 2001;21(3):377-82.

39. Issurin VB, Liebermann DG, Tenenbaum G. Effect of vibratory stimulation training on maximal force and flexibility. J Sports Sci 1994; 12(6):561-6.

40. Cardinale M, Bosco C. The use of vibration as an exercise intervention. Exerc Sport Sci Rev 2003;31(1):3-7.

41. Lundeberg T, Abrahamsson P, Bondesson L, Haker E. Effect of vibratory stimulation on experimental and clinical pain. Scand J Rehabil Med 1988;20(4):149-59.
42. Sands WA, McNeal JR, Stone MH, Russell EM, Jemni M. Flexibility enhancement with vibration: Acute and longterm. Med Sci Sports Exerc 2006;38(4):720-5.

43. Cronin J, Nash M, Whatman C. The acute effects of hamstring stretching and vibration on dynamic knee joint range of motion and jump performance. Physi Ther Sport 2008;9(2):89-6.

44. Padulo J, Oliva F, Frizziero A, Maffulli N. Muscles, Ligaments and Tendons Journal - Basic principles and recommendations in clinical and field Science Research: 2018 update. Muscles Ligaments Tendons J 2018;8(3):305-7. 